\title{
NanoSIMS and TEM: Complementary Techniques in the Search for the Earliest
}

\section{Life on Earth}

\author{
D. Wacey, ${ }^{*} * *$ M. Saunders, ${ }^{*}$ and M. Kilburn*
}

* Centre for Microscopy, Characterisation and Analysis, The University of Western Australia, 35 Stirling Highway, Crawley, WA 6009, Australia

** School of Earth and Environment, The University of Western Australia, 35 Stirling Highway, Crawley, WA 6009, Australia

We here demonstrate the use of two complementary techniques [NanoSIMS and TEM using Focussed Ion Beam sample preparation] for investigating putative signs of early life. Two case studies illustrate that these techniques provide new in situ data on the nano-scale that can help constrain both the biological nature and true age of candidate signs of early Archean ( $\sim 3.5$ billionyear (Ga) old) life.

\section{Preservation of biological signals in stromatolites}

NanoSIMS was used to map biologically important elements within 3 stromatolites of different ages (modern, $\sim 2.7 \mathrm{Ga}, \sim 3.4 \mathrm{Ga}$ ) to test the preservation of biological signals on the nano-scale. In the modern stromatolite, NanoSIMS ion images (Fig. 1a) show very closely correlated distributions of carbon $\left({ }^{12} \mathrm{C}^{-}\right)$, nitrogen $\left({ }^{26} \mathrm{CN}^{-}\right)$and sulphur $\left({ }^{32} \mathrm{~S}^{-}\right)$, both spatially and in terms of qualitative intensity. These elements pick out organic laminations running from top left to bottom right across the field of view. Modern stromatolites are biologically mediated, formed by the trapping and binding of sediment and biologically-induced precipitation. Hence, the logical conclusion is that these organic laminations represent the remains of microbial communities and the covariance of carbon, nitrogen and sulphur represents a biochemical signal that can be preserved during stromatolite fossilisation. Similar distributions of $\mathrm{C}, \mathrm{N}$ and $\mathrm{S}$ are seen in the ancient stromatolite samples (Fig. 1b, c), although laminations are not well preserved in the $3.4 \mathrm{Ga}$ example because it has undergone significant metamorphism and recrystallisation. High resolution TEM data from the $3.4 \mathrm{Ga}$ stromatolite indicates that the carbon structure is consistent with a biological precursor and with the metamorphic grade of the rock (hence it is not a modern contaminant). This data suggests a biological component to stromatolite formation in some of Earth's earliest sedimentary environments.

\section{Microbes living on 3.4 billion-year-old pyrite $\left(\mathrm{FeS}_{2}\right)$}

Our recent discovery of rounded sedimentary pyrite grains in a $3.4 \mathrm{Ga}$ sandstone, coated with a black laminated material, and containing micron-sized rounded pits and channels raised the possibility that an ancient microbial community was living on these grains. If so, this would represent the oldest example of iron- and/or sulfur-oxidising bacteria in the rock record. Using NanoSIMS and TEM we were able to chemically and structurally analyse the black material and pyrite surfaces to determine if these structures were biologically mediated. NanoSIMS chemical maps revealed enrichments in carbon and nitrogen within the black material, and nitrogen enrichments were systematically associated with the pits and channels in the pyrite grain surfaces (Fig. 2a). This indicates that the black material is the carbonaceous remains of a biological community, and that the pits and channels are likely microbial trace fossils created by the 
attachment of microbes to the pyrite surface. TEM data obtained from FIB ultrathin sections across the pyrite boundary confirmed the presence of thin layers of carbon on the pyrite surface (Fig. 2b, c). TEM also revealed mineral precipitates associated with the carbon, including nano iron oxides belonging to the magnetite-maghaemite family, amorphous iron-aluminium-silicates, and amorphous silica. These are consistent with the products of phototrophic iron-oxidising bacteria in modern settings and strongly suggest that this metabolism was in operation at $3.4 \mathrm{Ga}$.
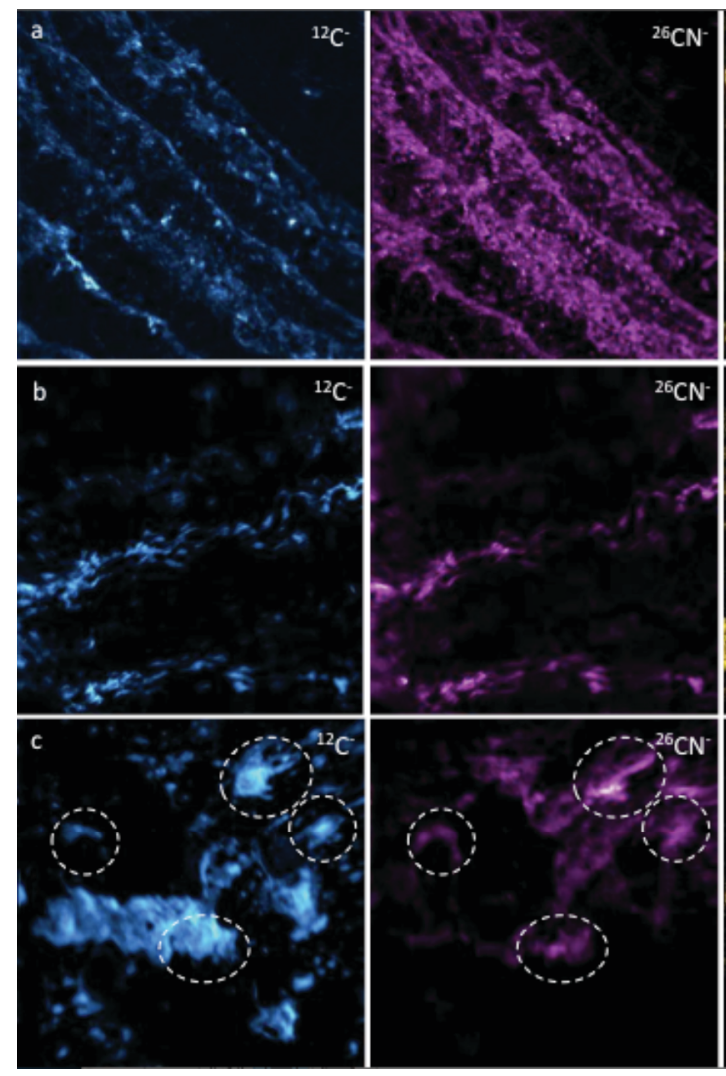

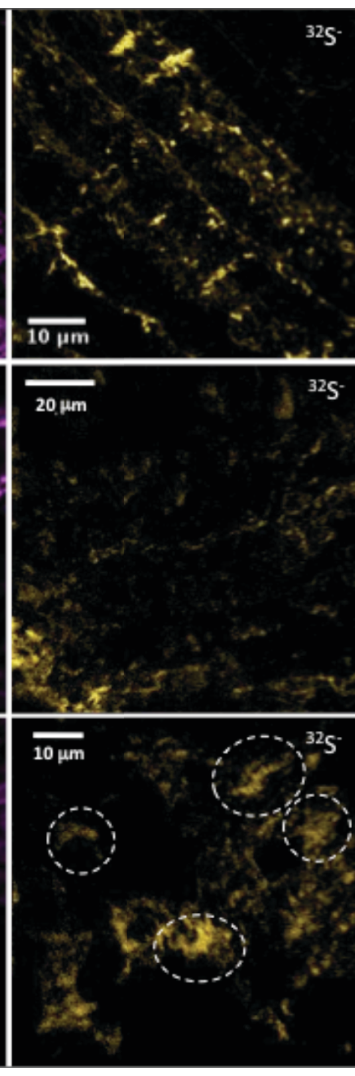

IG 1. I Go1IM1 ioG imI ges Iom modeIG I Gd I GsieGt stIomI tolites. I G oG IoMd elemental maps of ${ }^{12} \mathrm{C}^{-}$, ${ }^{26} \mathrm{CN}^{-}$ and ${ }^{32} \mathrm{~S}^{-}$from a modern Lake Thetis stromatolite, picking out well-preserved laminations. (b) Middle row, elemental maps of ${ }^{12} \mathrm{C}^{-},{ }^{26} \mathrm{CN}^{-}$and ${ }^{32} \mathrm{~S}^{-}$from a 2.7 $\mathrm{Ga}$ stromatolite from Western Australia. (c) Bottom row, elemental maps of ${ }^{12} \mathrm{C}^{-},{ }^{26} \mathrm{CN}^{-}$ and ${ }^{32} \mathrm{~S}^{-}$from a $3.4 \mathrm{Ga}$ stromatolite from Western Australia. Dashed ovals represent areas where there is particularly close spatial and intensity correlation of the three elements despite laminations only being poorly preserved.
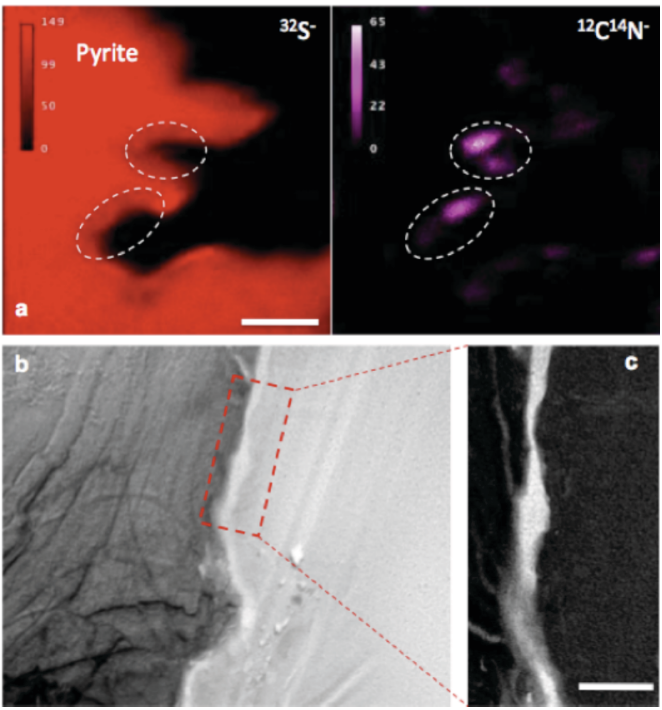

FIG 2. (a) NanoSIMS elemental maps of sulfur (left; measured as ${ }^{32} \mathrm{~S}^{-}$to indicate pyrite) and nitrogen (right; measured as ${ }^{12} \mathrm{C}^{14} \mathrm{~N}^{-}$) showing localised concentrations of nitrogen associated with microbial pits within the pyrite surface. (b) Bright field TEM image showing pyrite (dark grey; left), silica-rich cement (light grey; right), and narrow band of low mass material (white; centre) at the pyrite-silica boundary. (c) Energy-filtered TEM elemental map of carbon distribution within the boxed area in (b). Scale bar is $2 \mu \mathrm{m}$ for (a); $1 \mu \mathrm{m}$ for (b); $500 \mathrm{~nm}$ for (c).

This research was supported by the Australian Microscopy \& Microanalysis Research Facility, and The University of Western Australia. 